\title{
Autoinflammation leading to autoimmunity in adult-onset Still's disease: more than simple coincidence?
}

\author{
Larissa Valor-Méndez ${ }^{1,2^{*}} \mathbb{D}$, Bernhard Manger ${ }^{1,2}$, Alexander Cavallaro ${ }^{3}$, Stephan Achenbach ${ }^{4}$, \\ Georg Schett ${ }^{1,2}$ and Jürgen Rech ${ }^{1,2}$
}

\begin{abstract}
Background: Adult-onset Still's disease (AOSD) should be considered in the differential diagnosis of patients with endocarditis, with or without a cardiac decompensation.

Case presentation: We report the case of a 68-year-old Caucasian male diagnosed with AOSD after an initial acute manifestation of endocarditis with severe aortic acute manifestation of endocarditis with severe aortic insufficiency. The histological findings revealed Libman-Sacks endocarditis. He was treated with the IL-1 receptor inhibitor anakinra. Two years later the patient developed a symptomatic dilated cardiomyopathy with reduced ejection fraction (23.5\%) and functional anti-beta-1-adrenergic receptor antibodies, which was initially treated with plasmapheresis; anakinra was maintained. While his AOSD symptoms responded well, our patient presented with recurrent arthritis in multiple joints, dual-energy CT showed urate deposition compatible with a gouty arthropathy. Over 7 years, he presented with recurrent episodes of arthritis and the adjustment of dosages of colchicine and febuxostat was needed. In 2018, our patient died due to a deterioration of his underlying cardiac disease.
\end{abstract}

Conclusions: Only two cases with initial endocarditis prior to AOSD diagnosis have been published, and we are not aware of any other cases reporting $-\beta 1$ AR-Ab development with DCM and gout in the setting of AOSD treated with anakinra.

Keywords: Adult-onset Still's disease, IL-1 receptor inhibitor, Anakinra, Libman-Sacks endocarditis, Dilated cardiomyopathy, ANTI-beta-1-adrenergic receptor antibodies, Gout

\section{Background}

Adult-onset Still's disease (AOSD) is an uncommon systemic inflammatory disease on the clinical spectrum of autoinflammatory disorders and is characterized by high fever, arthralgia or arthritis, an evanescent salmoncolored skin rash and leukocytosis with neutrophilia [1]. The concept of a biphasic disease with initially activation

\footnotetext{
*Correspondence: Larissa.ValorMendez@uk-erlangen.de

${ }^{1}$ Department of Internal Medicine 3, Rheumatology

and Immunology, Friedrich Alexander University Erlangen-Nuremberg and Universitätsklinikum Erlangen, Ulmenweg 18, Erlangen, Germany

Full list of author information is available at the end of the article
}

of the innate immune system, triggered by danger signals, which then can led to activation of the adaptive immune system if not stopped early effectively is actually the understanding of the pathophysiology [2]. AOSD is a rare disorder with potential cardiac involvement, serosal involvement occurs in $25 \%-60 \%$ of patients and might be severe, while pericarditis, myocarditis, cardiac tamponade are less prevalent. Endocardial involvement is rare, and can present as non-infective endocarditis [1, 3, 4]. The IL-1 receptor antagonist (IL-1R $\alpha$ ) anakinra, which inhibits both IL- $1 \alpha$ and IL- $1 \beta$ activity has been approved for the treatment of $\operatorname{AOSD}[2,5,6]$.

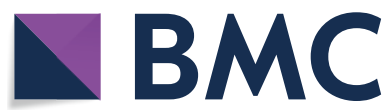

(c) The Author(s) 2021. Open Access This article is licensed under a Creative Commons Attribution 4.0 International License, which permits use, sharing, adaptation, distribution and reproduction in any medium or format, as long as you give appropriate credit to the original author(s) and the source, provide a link to the Creative Commons licence, and indicate if changes were made. The images or other third party material in this article are included in the article's Creative Commons licence, unless indicated otherwise in a credit line to the material. If material is not included in the article's Creative Commons licence and your intended use is not permitted by statutory regulation or exceeds the permitted use, you will need to obtain permission directly from the copyright holder. To view a copy of this licence, visit http://creativecommons.org/licenses/by/4.0/. The Creative Commons Public Domain Dedication waiver (http://creativeco mmons.org/publicdomain/zero/1.0/) applies to the data made available in this article, unless otherwise stated in a credit line to the data. 


\section{Case presentation}

We report the case of a 68-year-old Caucasian male. On presentation in 2009, he had dyspnea that worsened within 4 weeks, a transesophageal echocardiography demonstrated endocarditis with severe aortic insufficiency. The patient was referred to the cardiology department with ineffective antimicrobial treatment still suffering from intermittent fever, chills, lymphadenopathy and retrospectively myalgia and arthralgia in knees, ankles and shoulders at least for the last 6 months. Pharyngitis and skin rash were denied. The laboratory findings included elevated high Creactive protein (CRP, $335.2 \mathrm{mg} / \mathrm{l})$, leukocytosis $(18.96 \times 103 /$ $\mu \mathrm{l}$ with neutrophilia $(84 \%)$, anemia $(8.6 \mathrm{~g} / \mathrm{dl})$, thrombocytosis $(470 \times 103 / \mu \mathrm{l})$ and elevated serum ferritin (2923 ng/ml). Possible infectious diseases/toxic causes and malignancies were ruled out. He fulfilled the Yamaguchi diagnosis criteria for AOSD [7] at that time point ( 3 major: leukocytosis $>10,000 / \mathrm{mm} 3$ with $>80 \%$ polymorphonuclear cells, arthritis lasting over 2 weeks, fever and 2 minor criteria: negative antinuclear antibody/negative rheumatoid factor and lymphadenopathy). Toxic causes, malignancies, infectious diseases (including borreliosis and brucellosis), rheumatic diseases such as vasculitis or systemic erythematous lupus, in the frame of a similar workout as described by Ruscitti et al. were ruled out [8].

Treatment with the IL-1 receptor inhibitor anakinra (100 mg s.c./d) was started. Immediately a CRP, leukocytosis and ferritin normalization occurred. Preoperatively anakinra was stopped and our patient underwent heart surgery with insertion of a mechanical aortic valve. The microbiological and macroscopic findings demonstrated sterile pocket valve parts, partly translucent with focal polypose-nodular yellowish deposits. The histological findings showed an endocardial duplication with moderate fibrosclerosis and florid inflammation with neutrophilic granulocytes in addition to a lympho-plasmocytic inflammatory infiltrate and isolated eosinophilic granulocytes, fibrin and fibrinous infiltrates; which were highly suspected for Libman-Sacks endocarditis (Fig. 1A, B). Spironolactone und coumarin were added to his routine medication. He had no family history of rheumatic or inflammatory diseases; his treatment included losartan, metoprolol, ramipril und torasemide due to his arterial
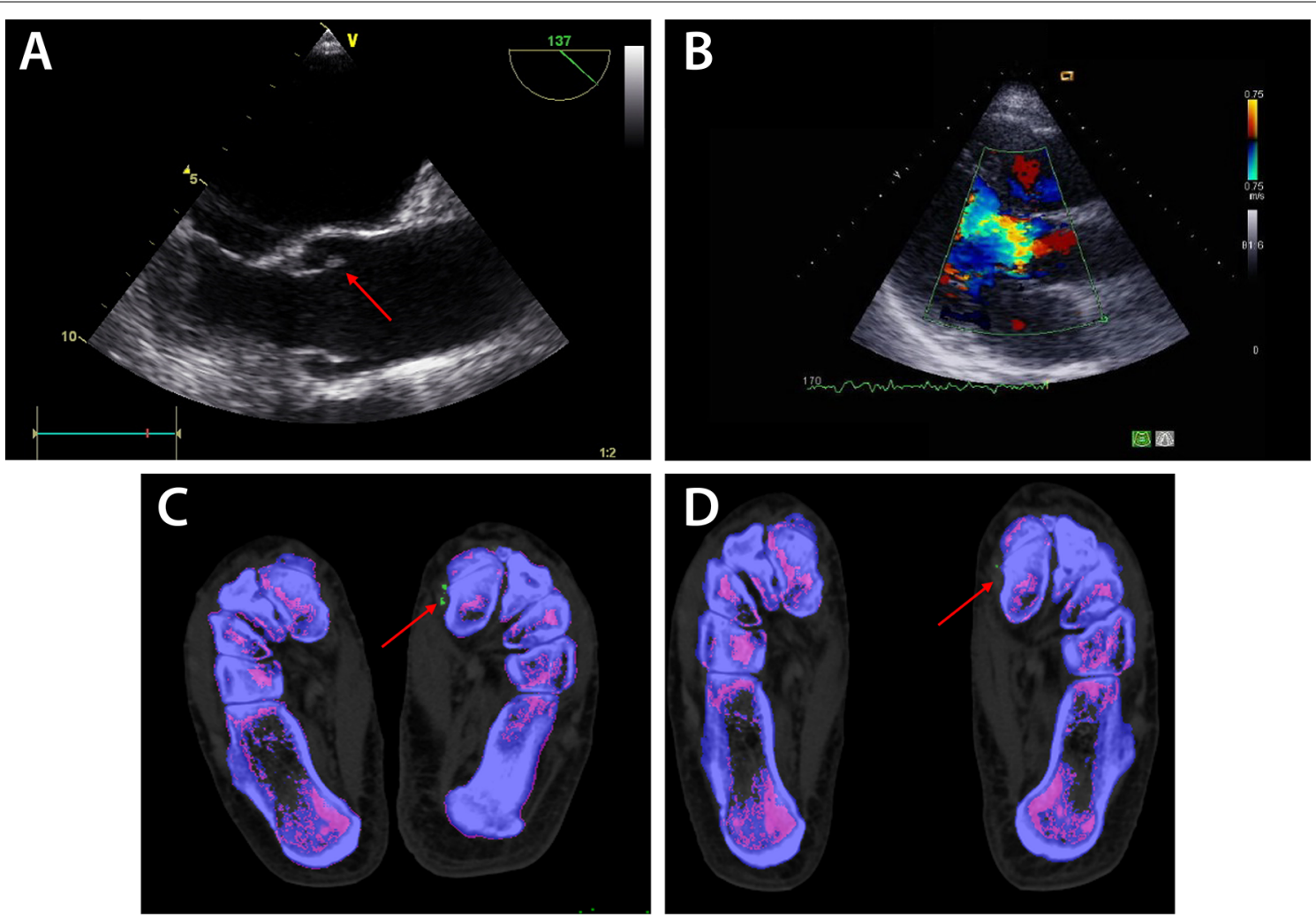

Fig. 1 A, B Two-dimensional transesophageal echocardiography, suspected endocarditis on aortic valve (red arrow) with severe regurgitation seen on color flow imaging (B). C Urate deposition (green dots marked by red arrow) in dual-energy CT. D Five months later, urate depositions (red arrow) were partially reduced 
hypertension and a mild renal insufficiency, he was a former smoker and had a previous knee surgery without complications.

Inflammation parameters increased immediately the day after cardiac surgery, so anakinra was re-started. Two years later the patient developed a symptomatic dilated cardiomyopathy (DCM) with a strongly reduced ejection fraction (23.5\%) and functional anti-beta-1-adrenergic receptor antibodies (anti- $\beta 1 \mathrm{AR}-\mathrm{Ab}$ ) were found, his AOSD was by that time well controlled and other causes for DCM including cardiac amyloidosis were explored and ruled out. These antibodies might bind to and constitutively stimulate the $\beta 1 \mathrm{AR}$ to induce $\beta 1 \mathrm{AR}$ desensitization/downregulation and pathological cardiac remodeling, have been associated with the pathogenesis of DCM and correlate with a poor prognosis [5].

Therefore, we performed nine cycles of daily plasmapheresis, while anakinra was maintained. Additionally, we added two doses of rituximab $1000 \mathrm{mg}$ i.v. each. Both were well tolerated and efficient; our patient recovered to an ejection fraction to $40 \%$ and was stable under tight cardiologic monitoring for the next couple of years. After discharge, we initiated treatment with azathioprine $50 \mathrm{mg} /$ day and continued the anakinra therapy.

While his AOSD symptoms were responding well to anakinra, our patient presented another 4 years later with recurrent arthritis of both ankles, related to elevated uric levels acid at $16.5 \mathrm{mg} / \mathrm{dl}$ and CRP at $55.6 \mathrm{ml} / \mathrm{l}$. Dualenergy CT (Fig. 1C) showed urate deposition metatarsophalangeal, in the left dorsal tibiotarsal joints, in the tendon attachment of the left tibialis anterior muscle and plantar, marginal sclerosed osteolysis and erosions in the tarsus. Tophaceous gout was diagnosed and treatment with colchicine and febuxostat was started. Five months later, urate depositions were partially reduced, in part constant but was still in the context of the gouty arthropathy (Fig. 1D).

Over 7 years, he presented with recurrent episodes of arthritis and the adjustment of dosages of colchicine and febuxostat was needed. In 2018, our patient died due to a deterioration of his underlying cardiac disease.

\section{Discussion and conclusions}

AOSD and gout are considered polygenetic auto-inflammatory diseases and their clinical manifestations are thought to result from exaggerated activation of innate immune pathways. Both diseases display a recurrent episodic course and respond well to anti-IL-1 treatment. Autoinflammatory diseases may develop chronic disease manifestations that suggest adaptive immune activation as well. In this context, it has been also hypothesized that the development of pathogenic autoantibodies such as anti- $\beta 1 \mathrm{AR}-\mathrm{Ab}$ might occur through autoimmunization.
This is consistent with alterations in humoral/cellular immunity, antigen mimicry and with injury-induced release of autoantigens.

At presentation, our patient developed a Libman-Sacks endocarditis. Even under control of the IL-1 pathway with anakinra, he developed anti- $\beta 1 \mathrm{AR}-\mathrm{Ab}$ and a later gouty arthropathy. Was the standard $100 \mathrm{mg} /$ day dose of anakinra not sufficient to suppress IL-1 bioactivity in this specific patient? Might all these episodes be immunologically related? On the one hand, a recent publication describes anti-IL-1 blockade in monogenetic and complex autoinflammatory diseases developing complications and/or a chronic disease course in which different disease mechanisms, including adaptive immune pathways seem to play a role [9]. On the other hand, T-lymphocyte activation via $\beta 1-A R$ autoantibodies causes IL-6 release, which could sustain a vicious cycle. Although the mechanism of initiation of this antibody formation is unknown, activated toll-like receptor-9 might explain the connection between innate and adaptive immunity [9]. We report this case to share our experience, which provides further evidence that AOSD should be considered in the differential diagnosis of patients with endocarditis, with or without a cardiac decompensation. To the best of our knowledge, only two cases with initial endocarditis preceding AOSD diagnosis have been published [3, $10]$ and we are not aware of other cases reported of anti$\beta 1 \mathrm{AR}-\mathrm{Ab}$ development with DCM and gout in the frame of AOSD treated with anakinra.

\section{Abbreviations \\ AOSD: Adult-onset Still's disease; IL-1Ra: IL-1 receptor antagonist; CRP: Creactive protein; DCM: Dilated cardiomyopathy; Anti- $\beta 1$ AR-Ab: Anti-beta- 1 -adrenergic receptor antibodies.}

\section{Acknowledgements}

Timo Meinderink.

\section{Authors' contributions}

JR, BM, AC, GS, and SA have made substantial contributions to the patient's diagnosis, treatment and follow-up. LV-M and JR wrote the manuscript with input from all authors. All authors have given final approval of the version to be published. All authors read and approved the final manuscript.

\section{Funding}

Open Access funding enabled and organized by Projekt DEAL. No financial support was received from any funding bodies in the public or commercial to carry out the work described in this manuscript.

\section{Declarations}

Ethics approval and consent to participate

Written informed consent was obtained from the patient's family. Standard ethics approval \#157_20 B and the TARDA database.

\section{Consent for publication}

The patient involved in this case report regrettably passed away due to his condition. 


\section{Competing interests}

None to declare.

\section{Availability of data and materials}

Supporting data can be anytime accessed in our files.

\section{Author details}

'Department of Internal Medicine 3, Rheumatology and Immunology, Friedrich Alexander University Erlangen-Nuremberg and Universitätsklinikum Erlangen, Ulmenweg 18, Erlangen, Germany. ${ }^{2}$ Deutsches Zentrum Für Immuntherapie (DZI), FAU Erlangen-Nürnberg and Universitätsklinikum Erlangen, Erlangen, Germany. ${ }^{3}$ Department of Radiology, Friedrich Alexander University Erlangen-Nuremberg and Universitätsklinikum Erlangen, Erlangen, Germany. ${ }^{4}$ Department of Internal Medicine 2, Cardiology. Friedrich Alexander University Erlangen-Nuremberg and Universitätsklinikum Erlangen, Erlangen, Germany.

Received: 20 April 2021 Accepted: 8 September 2021

Published online: 20 September 2021

\section{References}

1. Bagnari V, Colina M, Ciancio G, Govoni M, Trotta F. Adult-onset Still's disease. Rheumatol Int. 2010;30(7):855-62.

2. Nigrovic PA. Review: is there a window of opportunity for treatment of systemic juvenile idiopathic arthritis? Arthritis Rheumatol. 2014;66(6):1405-13.

3. Zenagui D, De Coninck JP. Atypical presentation of adult Still's disease mimicking acute bacterial endocarditis. Eur Heart J. 1995;16(10):1448-50.
4. Bodard Q, Langlois V, Guilpain P, Le Quellec A, Vittecoq O, Noel D, et al. Cardiac involvement in adult-onset Still's disease: Manifestations, treatments and outcomes in a retrospective study of 28 patients. J Autoimmun. 2021;116:102541.

5. Dinarello CA, van der Meer JW. Treating inflammation by blocking interleukin-1 in humans. Semin Immunol. 2013;25(6):469-84.

6. Pouchot J, Arlet JB. Biological treatment in adult-onset Still's disease. Best Pract Res Clin Rheumatol. 2012;26(4):477-87.

7. Masson C, Le Loet X, Liote F, Dubost JJ, Boissier MC, Perroux-Goumy L, et al. Comparative study of 6 types of criteria in adult Still's disease. J Rheumatol. 1996;23(3):495-7.

8. Ruscitti P, Cipriani P, Masedu F, lacono D, Ciccia F, Liakouli V, et al. Adultonset Still's disease: evaluation of prognostic tools and validation of the systemic score by analysis of 100 cases from three centers. BMC Med. 2016;14(1):194.

9. TerHaar NM, Jansen MHA, Frenkel JF, Vastert SJ. How autoinflammation may turn into autoimmune inflammation: Insights from monogenetic and complex IL-1 mediated auto-inflammatory diseases. Clin Immunol. 2020;219:108538.

10. Saraux A, Binard A, Devauchelle-Pensec V, Jobic Y, Jousse-Joulin S. Rightsided native valve endocarditis revealing adult-onset Still disease. Ann Intern Med. 2008;149(7):517-9.

\section{Publisher's Note}

Springer Nature remains neutral with regard to jurisdictional claims in published maps and institutional affiliations.
Ready to submit your research? Choose BMC and benefit from:

- fast, convenient online submission

- thorough peer review by experienced researchers in your field

- rapid publication on acceptance

- support for research data, including large and complex data types

- gold Open Access which fosters wider collaboration and increased citations

- maximum visibility for your research: over $100 \mathrm{M}$ website views per year

At BMC, research is always in progress.

Learn more biomedcentral.com/submissions 